\title{
8
}
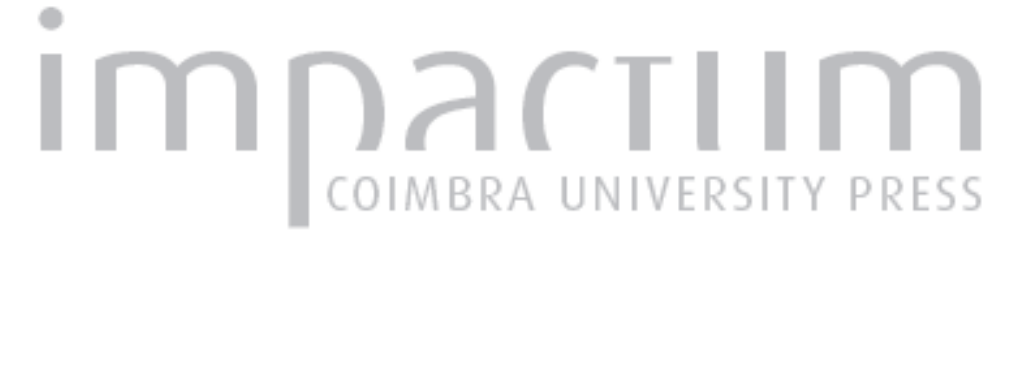

\section{A mercantilização da natureza e o aquecimento global: o papel da mídia}

Autor(es): $\quad$ Zangalli Junior, Paulo Cesar; Sant'Anna Neto, João Lima

Publicado por: Associação Portuguesa de Riscos, Prevenção e Segurança; Imprensa da Universidade de Coimbra

URL persistente:

URI:http://hdl.handle.net/10316.2/38052

DOI:

DOI:http://dx.doi.org/10.14195/1647-7723_22_2

Accessed : $\quad$ 26-Apr-2023 11:00:27

A navegação consulta e descarregamento dos títulos inseridos nas Bibliotecas Digitais UC Digitalis, UC Pombalina e UC Impactum, pressupõem a aceitação plena e sem reservas dos Termos e Condições de Uso destas Bibliotecas Digitais, disponíveis em https://digitalis.uc.pt/pt-pt/termos.

Conforme exposto nos referidos Termos e Condições de Uso, o descarregamento de títulos de acesso restrito requer uma licença válida de autorização devendo o utilizador aceder ao(s) documento(s) a partir de um endereço de IP da instituição detentora da supramencionada licença.

Ao utilizador é apenas permitido o descarregamento para uso pessoal, pelo que o emprego do(s) título(s) descarregado(s) para outro fim, designadamente comercial, carece de autorização do respetivo autor ou editor da obra.

Na medida em que todas as obras da UC Digitalis se encontram protegidas pelo Código do Direito de Autor e Direitos Conexos e demais legislação aplicável, toda a cópia, parcial ou total, deste documento, nos casos em que é legalmente admitida, deverá conter ou fazer-se acompanhar por este aviso.

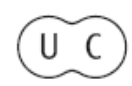




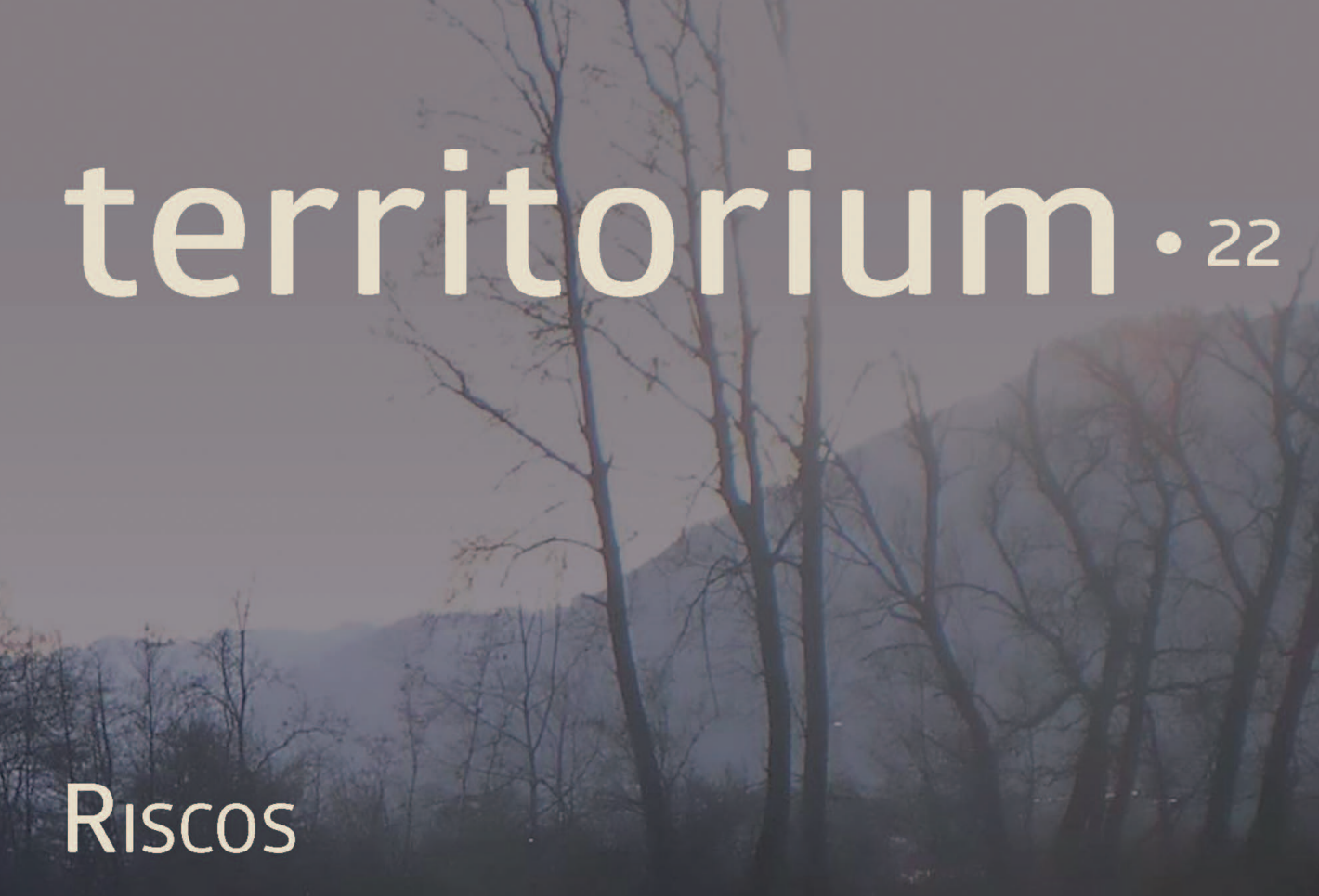

\section{TERRITÓRIOS DE CONVERGÊNCIA}

- Imprensa da Universidade de Coimbra Associação Portuguesa de:Riscos, Prevenção e Segurança 


\title{
A MERCANTILIZAÇÃO DA NATUREZA E O AQUECIMENTO GLOBAL: O PAPEL DA MÍDIA*
}

\author{
MERCHANTABILITY OF NATURE AND GLOBAL WARMING: THE MEDIA'S ROLE
}

Paulo Cesar Zangalli Junior

Departamento de Geografia, Grupo de Pesquisa GAIA FCT/UNESP Presidente Prudente pauloczangalli@gmail.com

João Lima Sant'Anna Neto

Departamento de Geografia, Grupo de Pesquisa GAIA FCT/UNESP Presidente Prudente jlsn57@uol.com.br

\section{RESUMO}

A proposta deste artigo é debater como o discurso ambiental tem sido incorporado pelo capital num processo de ambientalização e mercantilização da natureza com enfoque na construção e divulgação do discurso das mudanças climáticas globais pela mídia. A forma como a mídia divulga o tema, amplia e maximiza a perceção do risco e, muitas vezes, recria a realidade. Como considerações, aponta-se que a mídia atua como um agente legitimador de agendas públicas sobre as mudanças climáticas e, ao generalizar os discursos, contribui para a mercantilização do clima.

Palavras-chave: Mudança climática, mídia, ambientalização, sustentabilidade.

\section{ABSTRACT}

The purpose of this article is to discuss how the environmental discourse has been incorporated by capital in the process of greening and commodification of nature with a focus in the construction and dissemination of global climate change discourse in the media. The way that media reports the theme extends and maximizes the perception of risk and often recreates reality. As considerations, we point out that the media acts as a legitimizing agent of the public agenda on climate change and generalize the speeches, contributes to climate mercantilization.

Keywords: Climate change, media, greening, sustainability.

\section{RESUMEN}

Comercialización de la Naturaleza y Calentamiento Global: El Papel de los Medios de Comunicación - El propósito de este artículo es discutir como el discurso ambiental ha sido incorporado por el capital en el proceso de ambientalización y mercantilización de la naturaleza con un enfoque en la construcción y difusión del discurso del cambio climático global en los medios de comunicación. La forma como estos medios dan a conocer el tema extiende y maximiza la percepción del riesgo y, a menudo, recrea la realidad. Como consideraciones, se observa que los medios de comunicación actúan como un agente legitimador de las agendas públicas sobre el cambio climático y se generalizan los discursos, lo que contribuye a la mercantilización del clima.

Palabras clave: Cambio climático, medios de comunicación, ambientalizacón, sostenibilidad.

\section{RÉSUMÉ}

Nature de Valeur Marchande et Réchauffement Climatique: le Rôle des Médias - Le but de cet article est de discuter comment le discours de l'environnement a été intégrée par le capital dans le processus de verdissement et la marchandisation de la nature avec un accent sur la construction et la diffusion de discours sur le changement climatique dans les médias. La façon dont les médias rapporte le thème se étend et optimise la perception du risque et recrée souvent la réalité. Comment considérations, nous font remarquer que les actes de médias comme un agent de légitimation de l'ordre du jour public sur le changement climatique et de généraliser les discours, contribue à la marchandisation du climat.

Mots-clé: Le changement climatique, les médias, verdissement, la durabilité.

* O texto deste artigo corresponde a uma comunicação apresentada no III Congresso Internacional, I Simpósio Ibero-Americano e VIII Encontro Nacional de Riscos, tendo sido submetido em 30-01-2015, sujeito a revisão por pares a 30-04-2015 e aceite para publicação em 31-07-2015.

Este artigo é parte integrante da Revista Territorium, n. ${ }^{\circ} 22,2015,{ }^{\circ}$ RIscos, ISSN: 0872-8941. 


\section{Introdução}

As questões ambientais têm ocupado lugar de destaque nas discussões políticas e econômicas nas últimas décadas. As conferências para o desenvolvimento sustentável realizadas pela Organização das Nações Unidas (ONU) conferiram importância ainda maior ao tema.

A discussão que envolve a temática questiona a finitude dos recursos naturais utilizados no processo de produção capitalista e, ainda, aponta os impactos causados pela falta de preocupação generalizada com a natureza por parte das empresas.

As origens das questões ambientais, no entanto, encontram razões distintas. 0 movimento ambientalista combativo tem no seu cerne a crítica ao modelo de produção capitalista na busca por uma alternativa ao modelo hegemônico por meio de uma nova relação com o ambiente, adotando a busca por justiça ambiental como foco fundamental. Mas, há um ambientalismo utilitário que, segundo Acselrad (2010), se iniciou com o Clube de Roma que pressupõe medidas para assegurar a continuação da acumulação capitalista. Seu foco central é a economia de matéria e energia (recursos).

O processo de globalização recente fundado no meio técnico-científico-informacional situa um olhar globalizado sobre as questões ambientais. A preocupação com a camada de ozônio e, mais recentemente, o Aquecimento Global tomam centralidade nos discursos ambientais e tornam-se grandes causas tanto para uma vertente quanto para outra.

Aideia desse artigo é discutir como as questões ambientais têm sido incorporadas pelo mercado num processo de ambientalização dos discursos e mercantilização da natureza. Para isso, será debatido como a mídia atua na divulgação dos problemas ambientais e qual o seu papel frente a formulação de exigências para minimizar os riscos desse problema, tomando como base a cobertura do tema do Aquecimento Global.

Para isso foram analisados quatro dos principais veículos de informação de grande circulação no Brasil, durante oito anos de publicação. Tratam-se dos jornais Folha de S. Paulo e $\mathrm{O}$ Estado de S. Paulo, além das revistas semanais Veja e Época.

Na primeira parte do artigo apresentar-se-á uma discussão sobre as questões ambientais centradas na sociedade do risco e na sociedade do consumo considerando sempre as diferentes perspectivas ambientais.

A cobertura da mídia sobre o aquecimento global será discutida com apoio da sociologia ambiental, considerando principalmente o papel da mídia enquanto agente que formula, ou ao menos contribui para a formulação de exigências com relação aos problemas ambientais, situando a agenda ambiental nas agendas política, econômica e social.

Ambientalização, a mídia e o clima: a consolidação de uma agenda pública

As questões ambientais se originaram antes mesmo da conhecida preocupação principiada na década de 1960 e 1970. Para Schmidt (2008) as questões ambientais encontram três fases que se mesclam na contemporaneidade da discussão. A autora afirma que as primeiras leis de cunho ambiental têm início na Inglaterra, no século XIX e possuía caráter marcadamente conservacionista/naturalista. Ainda no mesmo século, uma segunda linha de pensamento ligada aos movimentos ambientalistas (se assim poderiam ser considerados) adquiriram um caráter muito mais humanista e considerava os desastrosos efeitos do processo de industrialização principalmente para a saúde da população operária urbana.

Porém, foi no âmbito dos fatos políticos que o campo temático do ambiente ganhou projeção diante das preocupações públicas, sociais e políticas. Cabe destacar a criação da ONU, da FAO e da UNESCO, além de uma midiatização dos discursos científicos, sejam individuais ou de grupos coletivos, como marcos importantes desse processo. Mas, para Schmidt (2008, p. 4) é a mescla do conservacionismo, as questões ligadas a demografia e a fome além do episódio da bomba atômica que fundará o movimento "ambientalista moderno".

Ao menos no Brasil, o movimento ambientalista historicamente caracterizou-se pelo perfil conservacionista/prote-cionista do meio ambiente. Porém, a maior parte do movimento ambientalista (ONGs, movimentos sociais, entidades ambientalistas internacionais, etc.) sempre buscou situar a luta contra a pobreza e a desigualdade social à luta por proteção ambiental. Porém, a preocupação mais recente passa ser a de como situar a luta por um meio ambiente sadio com o desenvolvimento econômico. (H. Acselrad, 2010).

A incorporação de perspectivas ambientais nos discursos sociais e econômicos é o que podemos chamar de ambientalização. H. Acselrad (2010, p.103) considera que "o processo de adoção de um discurso ambiental genérico por parte dos diferentes grupos sociais, como a incorporação concreta de justificativas ambientais para legitimar práticas institucionais, políticas, científicas etc" é o que melhor define esse processo.

A crescente ambientalização dos discursos, principalmente após a década de 1990, acabou por gerar um processo de institucionalização das práticas e dos movimentos ambientais e ambientalistas o que os dividem entre aqueles adeptos a um pragmatismo 
paraestatal ou paraempresarial e aqueles que fazem a crítica ao modelo de desenvolvimento dominante $(\mathrm{H}$. Acselrad, 2010, p. 105).

O grupo que mais se destacou certamente foi aquele ligado às questões governamentais e econômicas, ou seja, aqueles que ao se institucionalizarem, por um lado iniciaram uma associação com os governos e, de outro, a comercialização e outorga de licenças a empresas para que estas continuem suas atividades. Inicia-se um processo de formulação de manuais e cartilhas que padronizam a questão ambiental facilitando sua integração ao processo produtivo.

A incorporação do discurso ambientalista pela lógica de mercado acaba (re)significando a própria luta ambiental. Não se trata do fim da crítica ao modelo de desenvolvimento, mas sim da criação de um hedonismo ecológico e da expectativa de superar o problema por meio na inovação científica e tecnológica, porém, por outro lado renasce o discurso do ecologismo ligado aos movimentos sociais na busca por justiça socioambiental.

$\mathrm{Na}$ esfera econômica, no entanto, o ambiente, historicamente, é considerado um recurso necessário à produção e reprodução capitalista. Mas, essa concepção não se sustenta perante à eminente finitude desses recursos. Dá-se início a busca por uma maneira de se equacionar o desenvolvimento e a preservação do meio ambiente (enquanto recurso).

o mais próximo que se chegou de um modelo de desenvolvimento que medie a interação capital/ meio é a noção (ou conceito) de desenvolvimento sustentável apresentado no relatório Brundtland (1987) e amplamente difundida pela Conferência das Nações Unidas para o Meio Ambiente e Desenvolvimento que aconteceu no Rio de Janeiro em 1992.

O “conceito" de desenvolvimento sustentável apresentado busca uma maneira de conciliar crescimento econômico, equidade social e preservação ambiental para atender as necessidades do presente sem comprometer a possibilidade de as gerações futuras atenderem às suas próprias necessidades (CMMAD, 1988).

A construção do conceito de sustentabilidade é um tanto quanto controversa e está longe de findar-se. $\mathrm{Na}$ busca pela melhor definição encontra-se sempre como base a construção de modelos econômicos, o que pode facilmente sugerir que a noção de sustentabilidade não surgiu para atender a preservação ambiental, mas sim a maximização e melhor utilização dos recursos por aqueles detentores dos meios de produção (P. Zangalli JR, 2013a).

No entanto, a implementação de algumas medidas pôde ser percebida tais como a consolidação do princípio da precaução, as taxas de poluidor-pagador, as licenças de emissões para uso de energias não renováveis (mercado de carbono) dentre outras, todas elas consideradas medidas que reduzem os impactos da economia no meio ambiente. Nesse sentido, os impactos ao meio ambiente antes considerado uma externalidade negativa começa a ser considerando como parte do processo produtivo, podendo inclusive gerar novos meios de se lucrar com a racionalização do uso e dos impactos no ambiente, ou seja, de custo ambiental à um novo ativo de produção.

Contemporânea a adoção dessas medidas podemos citar o surgimento de uma disciplina que busca a conciliação entre desenvolvimento e meio ambiente. Em 1987, em Barcelona, funda-se a Sociedade Internacional da Economia Ecológica com a publicação do livro Economia Ecológica de Joan Martínez-Alier e Klaus Schlüpmann. Este fato merece destaque porque é a economia ecológica, enquanto paradigma econômico, que vai nortear a "conciliação" entre o modelo econômico (neoliberal) e o meio ambiente (Montibeller et al., 2012).

A economia ecológica utiliza conceitos transdisciplinares que propõem o uso dos recursos renováveis de maneira consciente, na medida em que o ambiente possa se recuperar e uso dos recursos não renováveis em ritmo em que estes possam ser substituídos por recursos renováveis. Dessa forma, a concepção de natureza compreendida por essa ciência não rompe com o conceito de natureza consolidado com o modelo de produção capitalista, ou seja, conceito que separa o homem de uma primeira natureza ou da natureza enquanto recurso. A economia ecológica humaniza a natureza quase como protagonista, buscando respeitar os limites que esta imporia ao processo produtivo e depositando fé na superação dos impactos por meio da inovação tecnológica (Montibeller et al., 2012).

Para Acselrad (2010), no entanto, a crença na atuação técnico-científica pautada nos localismos (globalizados) em torno da formação de consensos é um processo que favorece a atuação de organismos multilaterais como governos, Banco Mundial, na tentativa de antecipar a atuação crítica, ao que Boltanski \& Chiapello (1999) vão chamar de "deslocamento", ou seja, "mudanças organizativas ou de critérios de alocação social pelas quais o capitalismo assegura continuidade a seus próprios mecanismos, contribuindo para esvaziar as críticas que lhes são dirigidas" (H. Acselrad, 2010, p. 107).

Para alguns autores (Sachs, 2000; Alier, 1998; Carneiro, 2005) a tentativa de conciliação entre mercado e ambiente, apesar de se apresentar como uma relação positiva para o meio ambiente, apenas reforça a lógica do mercado. Para Carneiro (2005), “a 'conciliação', no plano ideológico, das contradições entre a lógica e os 
fundamentos do sistema de produção de mercadorias e a sustentabilidade ambiental só pode ser feito num alto grau de abstração" o que o torna inviável.

Para Sachs (2000), o desenvolvimento sustentável renova o consenso da necessidade de desenvolvimento, ou seja, não há desenvolvimento sem sustentabilidade e não há sustentabilidade sem desenvolvimento. Dessa forma, a noção de desenvolvimento sustentável pode ser utilizada tanto para proteger quanto para agredir o meio ambiente. Assim, como aponta Barthes (1978):

"Ao incorporar a fala ambientalista - e seu potencial de questionamento das estruturas -, o discurso do mercado, amparado em uma simpática receptividade midiática, se apropria do discurso ambiental $e$ o despolitiza e descontextualiza, conjurando seu potencial transformador. Assim procedendo, não só elimina a ameaça e a crítica, renovando a legitimidade da dinâmica desenvolvimentista (...), mas acaba convertendo a própria preocupação ambiental em novo fator de reprodução do capital, mercantilizando a própria causa, seja na forma de produtos ditos "ecologicamente corretos ou na utilização imagética e estilizada na publicidade para associar a produtos $e$ atividades uma imagem ecológica" (Guimarães JR, 2011, p.241-242).

Esta transição de paradigmas ambientais é permeada por diferentes concepções de natureza. Certamente o conceito de natureza presente na consolidação do paradigma do desenvolvimento sustentável não é o mesmo conceito utilizado pelo movimento conservacionista/protecionista. A natureza antes entendida como naturata, passa a ser vista como um recurso e mais recentemente a conciliação de ambas as preocupações tenta (re)significá-las.

Isso fica evidente ao observar essas questões sobre duas perspectivas, a de uma sociedade de consumo e, também da sociedade de risco. A sociedade de consumo caracterizada pelo consumo massivo de bens e serviços encontra facilmente nas questões ambientais um produto facilmente mercantilizado. 0 consumo consciente ou sustentável é um excelente exemplo disso.

O consumo sustentável, inclusive, divide opiniões quanto a sua eficácia frente aos princípios ambientalistas. Para alguns autores (Portilho, 2005; Jacobi, 2006), o consumo sustentável representa:

"um salto qualitativo de complexa realização, na medida em que agrega um conjunto de características que articulam temas como equidade, ética, defesa do meio ambiente $e$ cidadania enfatizando a importância de práticas coletivas como norteadoras de um processo que, embora englobe os consumidores individuais, prioriza as ações na sua dimensão política" (Jacobl, 2006).
No entanto, é necessário destacar as ambiguidades desse processo. 0 consumo sustentável mantém no processo técnico-científico a saída para a superação da degradação ambiental, porém não faz a crítica ao modelo de produção e distribuição de bens. Assim, a responsabilidade pela degradação ambiental é transposta para o consumo e consequentemente para o consumidor que se torna o maior responsável pelas mudanças necessárias. Dessa forma há "transferências da atividade regulatória em dois aspectos: do Estado para o mercado, através de mecanismos de auto regulação, e do Estado e do mercado para o cidadão, através de suas escolhas de consumo" (Portilho, 2005).

$\mathrm{Na}$ sociedade de consumo a funcionalidade do que se consome se torna algo secundário, o que importa mesmo é o conjunto de simbolismos que se agrega a um objeto. 0 marketing é o que vai reafirmar a necessidade de se consumir aquele conjunto simbólico (Guimarães JR, 2011). No caso ambiental vende-se inclusive a ideia de que o consumidor ao "escolher" as empresas que respeitam o meio ambiente em detrimento das outras tem a capacidade de inferir na lógica de produção, quando na verdade trata-se de uma lógica totalmente contrária.

Dessa forma, o sentido de preocupação ecológica se esvai e o que resta é a conversão das questões ambientais em mera representação estética da natureza. A questão do consumo ambiental tem um caráter tão significante que na década de 1990, 80\% dos americanos e europeus se consideravam ambientalistas, o que remete a pensar que a criação de intensas campanhas publicitárias tenha construído tal sentimento (Guimarães JR, 2011).

$\mathrm{Na}$ abordagem da sociedade de risco, a sociedade industrial, caracterizada pela produção e distribuição de bens, teria se deslocado pela sociedade de risco, na qual a distribuição dos riscos geraria uma nova forma de capitalismo, ou seja, uma nova ordem global. No contexto apontado por Beck (1992), em que o próprio conceito de risco se confunde com o de globalização - os riscos não respeitam fronteiras, classes sociais, nações atribui-se valor a tudo, inclusive aos impactos possíveis dos problemas ambientais.

Para Veyret (2007) a noção de risco é vista como "objeto social e define-se com a percepção do perigo, da catástrofe possivel e, portanto, ele existe apenas em relação a um indivíduo, a uma sociedade que o apreende e com ele convive por meio de práticas específicas".

Sabe-se que a noção de risco se estabelece na relação conflituosa entre homem e ambiente em um processo de mutua influência. A percepção do risco é um componente fundamental na estruturação de resposta ao perigo, influenciando vários aspectos da vida individual e coletiva. Porém deve-se romper com a ideia de um evento natural agressor que atua sob uma 
sociedade que se coloca, de forma homogênea, como vítima. (Souza e, Zanella, 2009).

Assim, os riscos - ou ao menos a sua produção - estão intrinsecamente ligados à forma como as sociedades estão organizadas sobre a ênfase da inovação tecnológica, da mudança e, da pretensão de controlar e prever as consequências imprevisíveis das decisões, submetendo ao controle o incontrolável e principalmente sujeitando essas decisões a tentativas de gerar segurança nesses contextos (Costa, 2011). E isso será manipulado pela razão do conhecimento técnico-científico altamente desprovido de neutralidade.

Assim, globaliza-se cada vez mais, na percepção de uma responsabilidade comum, porém diferenciada, problemas que precisam ser debatidos na esfera do local. Esse processo nega as especificidades do local, padroniza soluções, atribui valores à natureza inserindo-a num contexto econômico, em que o processo de produção capitalista responsável pela degradação passa a ser a única solução para o problema.

Esse processo cíclico da ambientalização discursiva do mercado (Acselrad, 2010), da transferência das responsabilidades para o mercado e para o consumo (Portilho, 2005) amparado pela lógica do marketing ecológico (Guimarães JR, 2011) situa claramente a lógica da natureza às logicas do mercado contribuindo no processo de mercantilização da natureza. Todo esse processo é amparado pela produção e percepção dos riscos. 0 fato é que nesse processo de ambientalização do mercado, uma cultura de práticas ambientais começa a se criar no imaginário do público. A mídia tem um papel significativo na formulação desse processo.

Os meios de comunicação de massa têm um papel de destaque em várias etapas do processo de percepção do risco e da consolidação de uma "cultura ambiental". Para alguns autores a mídia ainda exerce, inclusive, um papel de divulgar a "informação científica” à população.

Assim, a análise a discussão que se apresenta refere-se aos dados obtidos com a análise de dois jornais diários de grande circulação no Brasil, a Folha de $\mathrm{S}$. Paulo e 0 Estado de S.Paulo e as revistas semanais Veja e Época. Foram analisados oito anos de publicação (2000-2008) e catalogadas todas as matérias que compunham parte das páginas dos veículos de comunicação. A análise se fez considerando vários elementos, desde a fonte da informação, o conteúdo do texto, passando pela parte gráfica e finalizando com a identificação dos principais conceitos e temáticas incorporadas. As análises que serão apresentadas nesse artigo referem-se, principalmente ao conteúdo e aos conceitos utilizados pela mídia para abordar o tema das mudanças climáticas globais. Ao todo foram analisadas 807 matérias de jornais e 95 de revistas semanais conforme podemos verificar na TABELA I.
TABELA I - Dados dos jornais analisados de acordo com cada veículo de comunicação.

TABLE I - Newspaper data analyzed according to each communication vehicle.

Quantidade de Matérias de acordo com cada veículo de comunicação

\begin{tabular}{|l|c|}
\hline \multicolumn{1}{|c|}{ Media } & $\begin{array}{c}\text { Quantidade de notícias } \\
\text { encontradas }\end{array}$ \\
\hline Folha de São Paulo & 447 \\
\hline O Estado de São Paulo & 360 \\
\hline Veja & 50 \\
\hline Época & 45 \\
\hline
\end{tabular}

Há diversas maneiras de interpretar o conteúdo e a forma com que a mídia comunica os problemas ambientais ao público. Schmidt (2008) apresenta ao menos quatro maneiras de se compreender a forma como a mídia atua perante os problemas ambientais, por meio da: a) agenda-setting; b) Cultivation-Analyses; c) abordagem construcionista e; d) abordagem interacionista.

A primeira perspectiva demonstra a capacidade da mídia em consolidar uma agenda científica/ambiental nas agendas políticas e sociais. Há nesse contexto alguns fatores essenciais para se fazer um problema ambiental recorrente nas diversas agendas. A atualidade do tema, sendo que quanto mais atual mais importante na opinião pública; a continuidade, ou seja, a recorrência ou a permanência desse problema tem forte impacto na opinião pública além da quantidade, uma vez que quanto maior o número de notícia mais notado esse problema se torna (ibdem, p. 88)

A perspectiva da Cultivation-Analyses refere-se à capacidade de transmissão de valores e simbolismos em uma cultura ambiental para seus mais distintos públicos. Essa estratégia contribui para o processo de mercantilização da natureza ou ambientalização do capital já foi discutida no caso do consumo sustentável. Porém, Schmidt (2008, p.92-93) apresenta um estudo de caso sobre um episódio de uma série televisiva chamada L.A Law que foi dedicado ao abate de árvores nos parques dos EUA. No episódio um lenhador que perdeu o braço está processando a empresa em que trabalhava por negligência e uma ONG ambientalista. 0 estudo mostrou que a percepção de diferentes telespectadores é genericamente diferente - de acordo com suas orientações sociais - mas há dimensões chaves que convergem, no caso do episódio, a imagem negativa do ativismo ambiental. 0 estudo mostrou que apesar das divergências a representação midiática atuava como uma espécie de caracterização universalizante, contribuindo para instaurar um discurso dominante, ideologicamente negativo frente a qualquer tipo de ativismo.

A perspectiva Construcionista (mais explorada nesse trabalho) relativiza o poder da mídia e denota a ela 
um papel importante na consolidação, inclusive das agendas-settings. A forma como a mídia contribui para a construção de um problema ambiental precisa considerar uma série de elementos, inclusive culturais. No caso dos problemas globais, no entanto, em que estes não são cotidianamente percebidos pela população sua importância é ainda maior.

Essa estratégia faz parte da consolidação de temas amplamente mídia-dependentes como o caso do "buraco" na camada de ozônio ou as mudanças climáticas na agenda pública, política e social. Trata-se de temas que serão amplamente consumidos na mídia, uma vez que não são cotidianamente percebidos. Assim, "Independentemente da cientificidade dos fenómenos, os media criam uma concepção pública específica do que eles significam, organizam o conhecimento sobre eles, constroem uma representação imagética. Ora é a partir desta que os problemas globais adquirem existência pública" (Schmidt, 2008, p. 91)

No caso específico da camada de ozônio, a maneira como o tema foi debatido criando uma sensação de catástrofe no imaginário da população deve-se em muito ao trabalho efetuado pela midiatização do tema. No caso das mudanças climáticas não é diferente. Em âmbito global cabe destaque à divulgação e o destaque que a mídia confere aos relatórios do IPCC (oficialismo), associados ao peso que Al Gore conferiu ao assunto "emprestando" sua imagem ao tema, principalmente na produção do livro e do filme Uma Verdade Inconveniente, renovando assim a importância que a ciência tem conferido ao aquecimento do planeta (Schimdt, 2008).

Por fim, o perfil interacionista refere-se às fontes e a diversificação das mesmas, permitindo inclusive um papel participativo dos agentes da ciência na comunicação das mensagens. No entanto a preferência dos meios de comunicação são as fontes oficiais de informação pois são estas que geram uma rotina de notícias para a mídia.

Da mesma forma Hannigan (1995) aponta que mais do que um fato, a notícia é "o produto de um sistema fixo de trabalho, cuja tarefa é impor um sentido de ordem e previsão no caos de múltiplos e, por vezes, não relacionadas acontecimentos e questões". Assim, é facilmente notável o interesse dos veículos de informação por uma rotina de notícias calendarizadas, como conferências oficiais, discussões públicas e excepcionalidades como eventos climáticos e sua repercussão no espaço.

$\mathrm{Na}$ cobertura da mídia brasileira sobre o aquecimento global esse oficialismo é facilmente notado nos dados analisados e, conforme pode se verificar nos dados apresentados na TABELA II. A quantidade de notícias dos jornais diários Folha de S.Paulo e O Estado de São Paulo são notoriamente maiores nos meses em que a COP acontece. Os anos em que o IPCC divulgou dois de seus relatórios oficiais (2001 e 2007) a cobertura midiática foi relativamente grande nesse período, diminuindo nos meses seguintes e voltando e ter espaço durante a COP de Marrakesh e Bali respectivamente (P. Zangalli JR, 2014).

TABELA II - Quantidade de matérias classificadas segundo as temáticas centrais.

TABLE II - Number of notices classified according maim issues.

Quantidade de matérias segundo classificação de interesse

\begin{tabular}{|lcc|}
\hline & $\begin{array}{c}\text { Folha de } \\
\text { S. Paulo }\end{array}$ & $\begin{array}{c}\text { O Estado de } \\
\text { S. Paulo }\end{array}$ \\
\hline $\begin{array}{l}\text { Conferências } \\
\text { Internacionais }\end{array}$ & 169 & 126 \\
\hline Pesquisas Científicas & 34 & 34 \\
\hline Impactos & 168 & 138 \\
\hline Mitigação & 28 & 16 \\
\hline Mudanças Climáticas & 11 & 10 \\
\hline Visão cética & 6 & 6 \\
\hline Economia & 31 & 30 \\
\hline
\end{tabular}

Fonte: (P. Zangalli JR, 2014). Source: (P. Zangalli JR, 2014).

Com isso, a mídia em geral reduz o rigor científico na cobertura dos fatos ambientais, quer exista ou não perigo nisso. Um exemplo é a entrevista com Alberto Figueiredo Machado, negociador chefe do Brasil na COP 11, publicada no dia 28 de novembro de 2005 no jornal Folha de S. Paulo. Nesta entrevista, o jornal apresenta aos seus leitores um glossário em que define mudança climática como "Conjunto de alterações dos padrões climáticos em decorrência do aquecimento global. Os riscos incluem aumento do nível do mar". Esta definição está longe do conceito adotado pela OMM: “todas as formas de inconstâncias climáticas, independentemente da sua natureza estatística, escala temporal ou causas físicas [.. ] que persista por mais de 30 anos" (P. Zangalli Jr, 2014).

A preferência pelos impactos é outro elemento que distancia a mídia do perfil científico. Comparando artigos publicados nos periódicos científicos Theoretical and applied climatology e Climatic Change, com os dados obtidos nos jornais Folha de S. Paulo e O Estado de S. Paulo, de acordo com os principais conceitos abordados, tanto pela ciência quanto pela mídia, percebe-se que a ciência prefere o debate sobre as mudanças climáticas com o devido rigor científico, enquanto a mídia exagera na utilização dos impactos, conforme pode-se verificar com a fig. 1.

O que de fato fica evidente é que a mídia atua como um agente legitimador de agendas públicas ambientais. A rotina de notícias pré-determinada, a preferência pelos impactos, o pouco interesse pelo o rigor científico é usado para (re)significar ainda mais o problema ambiental, o que não descaracteriza o debate científico sobre o fato, mas influenciam e maximizam a percepção do risco por parte do público. 


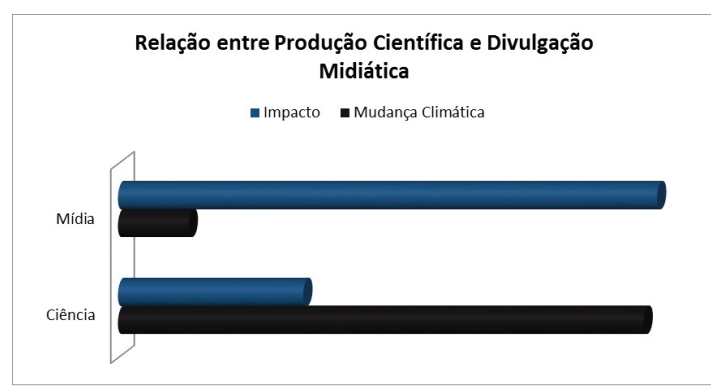

Fig. 1 - Relação entre Produão Científica e Divulgação da Mídia (Fonte: P. Zangalli JR, 2014).

Fig. 1 - Comparison between scientific literature and media disclosure (Source: P. Zangalli JR, 2014).

Há algumas características, inclusive, que são capazes de influenciar a percepção do problema, atenuando ou agravando a leitura que se faz da realidade. Pode-se citar a magnitude, duração, frequência, extensão em área, velocidade de deflagração e distribuição temporal de um evento específico, por exemplo (Souza e, Zanella, 2009 p. 37). Ainda nessa perspectiva, Whyte (1985) apresentou um conjunto de fatores associados a fenômenos climáticos adversos (QUADRO I). Esses fatores podem ser percebidos na abordagem midiática que elucida a dimensão que tomou o aquecimento global, principalmente depois de sucessivas ondas de calor no hemisfério norte.

Para além dos elementos já apresentados, Hanningan (1995) sugere a utilização de algumas estratégias para transmitir fatos jornalísticos. Segundo o autor, a mídia utiliza-se de quatro elementos essenciais para formular os problemas ambientais. 0 primeiro diz respeito ao paradigma social existente, ou seja, a mídia associa o problema a imagens de fácil percepção. Essa associação ecoa sobre esse paradigma, porém sem a capacidade de romper com o mesmo.
Essa estratégia contribui na construção dos valores e na formulação dos simbolismos que vai proporcionar o processo de ambientalização do mercado, ou mercantilização da natureza. É o que sugere a matéria da revista Época intitulado "compras para salvar o mundo" (fig. 2) que confere ao consumo um potencial transformador do processo produtivo que este não possui de fato. Assim, há uma generalização simbólica que ressoa no paradigma socioeconômico, porém sem nenhum potencial questionador. Sugere-se que o problema não é o consumo excessivo da sociedade capitalista moderna, mas sim, o consumo de produtos ecologicamente/ambientalmente predatórios.

$\mathrm{O}$ segundo elemento destacado se refere à necessidade de o problema ambiental estar articulado através das agendas políticas e científicas correndo o risco, caso não atendam a esses requisitos, de não se legitimar como um

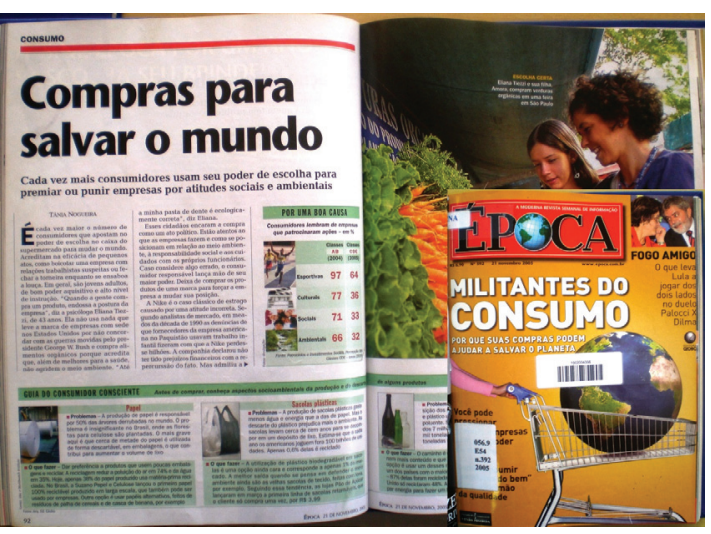

Fig. 2 - Militantes do Consumo (Fonte: Revista Época, n 392, 21 de novembro de 2005).

Fig. 2 - Consumption activists (Source: Época magazine $n^{\circ} 392$, 21 of November of 2005).

QUADRo I - Processos climáticos capazes de influenciar a percepçãodos indivíduos.

FRAME I - Climate processes that can influence individuals perceptions.

\begin{tabular}{|cc|}
\hline Forte Influência & Fraca Influência \\
\hline Alta probabilidade de ocorrência & Baixa probabilidade de ocorrência \\
\hline Curto intervalo de recorrência & Impactos nunca experimentados \\
\hline Expectativa de que ocorra em breve & Expectativa de que ocorra no futuro \\
\hline Evento extremo & Baixa variação em torno do habitual \\
\hline Evento imaginável, de fácil definição & Início e fim difíceis de identificar \\
\hline Fortes consequências & Fracas consequências \\
\hline Impacto direto sobre o bem-estar & Efeitos indiretos sobre o bem-estar \\
\hline Perdas de vidas humanas & Sem perdas de vidas humanas \\
\hline Vítimas identificáveis & Vítimas tratadas estatisticamente \\
\hline Impactos concentrados & Impactos aleatórios \\
\hline Razoável certeza de que irá ocorrer & Incerteza de que irá ocorrer \\
\hline Mecanismos e efeitos inteligíveis & Mecanismos e efeitos não entendidos \\
\hline Impactos dramáticos & Impactos pouco perceptíveis \\
\hline
\end{tabular}


problema na agenda dos meios de comunicação social. A construção da agenda ambiental e sua capacidade de influência é notória, principalmente com a constante preocupação de consolidar um consenso científico perante ao público em geral. Isso é observado em matérias como "O acordo sobre mudanças climáticas: consenso por meio da ciência" estampada no jornal Folha de São Paulo em 28 de julho de 2001. Em realidade o "consenso" abordado pela matéria não é científico, mas sim "político", já que os acordos são protagonizados pelos agentes que representam os estados nacionais.

O terceiro elemento, destacado, é a “dramatização social". Como as notícias estão roteirizadas e calendarizadas, essa dramatização se torna algo simples de se estabelecer, talvez por isso o aquecimento global só se torna uma preocupação midiática depois do forte verão de 1988. São os eventos extremos que permitiram a roteirização em formato de drama social. Estabelecese o problema que necessita de uma solução, assim a ação antrópica passa de causadora do problema para sua única solução. As imagens nesse caso são mais importantes que as próprias palavras. As capas da revista Veja (fig. 3) exemplificam bem essa estratégia (Zangalli JR, 2013).

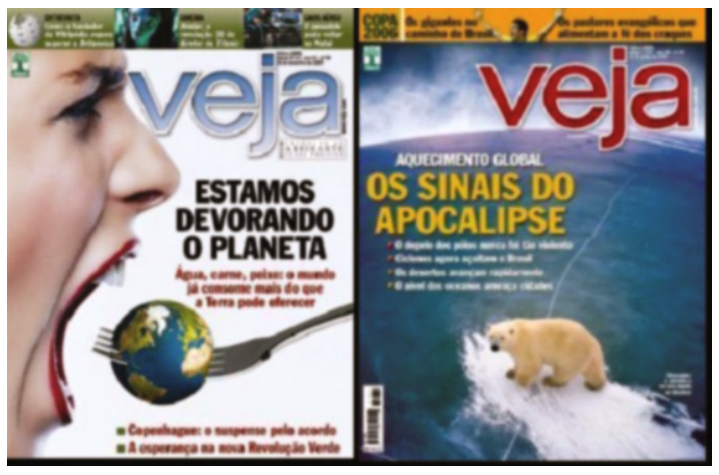

Fig. 3 - Os sinais do Apocalipse (Fonte: Revista Veja, ed. 1961, 21 de junho de 2006; Veja, ed. 2143, 16 de dezembro de 2009).

Fig. 3 - The Apocalypse Signs (Source: Veja Magazine, ed. 1961, 21 de June of 2006; Veja, ed. 2143, 16 december of 2009).

Quarto elemento, ainda segundo Hannigan (1995), é a associação do problema ambiental com o presente ao invés de um futuro distante. É nesse sentido que o risco aos impactos do clima é percebido e maximizado. 0 risco futuro se reflete na vulnerabilidade do agora, essa estratégia pode ser verificada no QUADRO II.

Assim, ao mesmo tempo em que legitima as mudanças climáticas em um dos maiores problemas ambientais, a mídia induz a percepção dos riscos e a insere no contexto da globalização econômica, fundada na sociedade do risco e, consequentemente, como afirma Leff, (apud Oliveira, 2012) no processo de naturalização da mercantilização da natureza, em que o processo de produção capitalista passa de causa a solução do problema.
Vê-se, logo, que há dois modelos de ambientalização colocados em jogo, aquele que atende à modernização ecológica - pautada na lógica produtiva, na precificação da natureza, carregada em simbolismo, equacionamento do meio ambiente na lógica da propriedade privada, do privilégio ao invés do direito - e aquele pautado na justiça ambiental - que faz a crítica ao modelo de produção e aponta a desigual exposição ao risco como fruto da acumulação de riqueza como resultado da penalização ambiental dos despossuídos $(\mathrm{H}$. Acselrad, 2010).

0 rumo que se tem verificado na implementação de uma economia verde tem privilegiado a modernização ecológica em detrimento da justiça ambiental. A forma como a mídia atua na criação dos problemas ambientais contribui para esse processo.

É cada vez mais necessário dar novo sentido à percepção e a relação com a natureza buscando um modelo que garanta igualdade de acesso aos recursos proporcionando que nenhum grupo social suporte uma exposição exagerada aos riscos. Porém, isso só irá acontecer diante da luta social e ambiental criando na concepção das questões ambientais um espaço de construção de justiça e não apenas da razão do mercado.

\section{Conclusão}

As questões ambientais possuem distintas concepções na atualidade. A luta por justiça social, objetivo do movimento ambientalista combativo compreende o ambiente para além da razão técnico-científica considerando suas razões socioculturais, ou seja, não há natureza sem sujeito, logo há distintas significações da natureza e distintas formas de uso de acordo com cada sociedade e cada cultura.

No entanto, há um processo de ambientalização da lógica de mercado que contribui para a mercantilização da natureza. Atribui-se valor à aquilo que não tem preço, privilegia a lógica da propriedade privada e da acumulação de riqueza em função da exposição desigual aos riscos ambientais.

Nessa lógica há um conjunto de valores simbólicos que, inclusive, transpõe a responsabilidade do impacto ambiental e da mudança de paradigma para o consumo enfraquecendo o foco sobre o processo de produção e do consumo, responsável pela atual crise ambiental.

A mídia atua, frente aos danos ambientais, como um agente legitimador de agendas públicas, conferindo a visibilidade necessária para que um problema ambiental se efetive nas agendas política e social. A cobertura das mudanças climáticas deixa isso evidente ao se notar a utilização de elementos como a calendarização dos fatos e a preferência pelos impactos. 
QUADRo II - Versão oficial apresentada pela mídia.

Frame II - Official version of media.

\begin{tabular}{|c|c|c|}
\hline \multicolumn{3}{|c|}{ A NOVA GEOGRAFIA } \\
\hline $\begin{array}{l}\text { O que se previa } \\
\text { há dez anos }\end{array}$ & Como a Terra já mudou & $\begin{array}{c}\text { As conseqüências } \\
\text { para nossa vida }\end{array}$ \\
\hline $\begin{array}{l}\text { O clima ficará mais quente, } \\
\text { alterando as tradicionais } \\
\text { divisões entre zonas } \\
\text { temperadas e tropicais do } \\
\text { planeta. Mesmo que um ou } \\
\text { outro ano seja eventualmente } \\
\text { mais frio, a média geral será } \\
\text { mais alta }\end{array}$ & $\begin{array}{l}\text { A média de aquecimento do planeta } \\
\text { foi de } 0,6 \text { grau nos últimos cem anos, } \\
\text { a maior do milênio. Os últimos dez } \\
\text { anos, com exceção de } 1996 \text {, foram os } \\
\text { mais quentes registrados desde } 1861\end{array}$ & $\begin{array}{l}\text { Áreas originalmente temperadas como a } \\
\text { Flórida já sofrem com doenças tropicais, } \\
\text { como malária, típica de regiões quentes e } \\
\text { úmidas. No ano passado, os furacões Charles, } \\
\text { Frances, Ivan e Jeamme atingiram o Estado } \\
\text { e causaram US\$ } 30 \text { bilhões em prejuízos, na } \\
\text { temporada de furacões mais cara da História } \\
\text { até então }\end{array}$ \\
\hline $\begin{array}{l}\text { As geleiras localizadas nas } \\
\text { montanhas serão reduzidas. } \\
\text { o derretimento vai provocar } \\
\text { enchentes nas cidades } \\
\text { localizadas em vales dos Andes } \\
\text { e do Himalaia }\end{array}$ & $\begin{array}{l}\text { Das dez maiores geleiras de } \\
\text { montanhas, oito apresentaram } \\
\text { derretimento mais rápido nos últimos } \\
\text { cinco anos do que nas quatro décadas } \\
\text { anteriores }\end{array}$ & $\begin{array}{l}\text { A geleira da Montanha Gemsstock, nos } \\
\text { Alpes suíços, foi coberta com um colchão } \\
\text { térmico artificial durante o último verão }\end{array}$ \\
\hline $\begin{array}{l}\text { Parte da Antártida e da } \\
\text { Groenlândia derreterá. } 0 \\
\text { deslocamento dessa grande } \\
\text { massa de gelo, que estava em } \\
\text { terra firme, elevará o nível do } \\
\text { mar }\end{array}$ & $\begin{array}{l}\text { O derretimento de geleiras na } \\
\text { Antártida contribui com cerca de } 0,2 \\
\text { milímetro por ano no aumento do } \\
\text { nível do mar, e a Groenlândia com } \\
0,1 \text { milímetro. Estima-se que o nível } \\
\text { do oceano tenha aumentado entre } 10 \\
\text { e } 20 \text { centímetros no século XX }\end{array}$ & $\begin{array}{l}\text { A elevação média de } 1,1 \text { milímetro por } \\
\text { ano no nível do mar em Santos pode } \\
\text { ser a causa das ressacas violentas que } \\
\text { têm atingido a cidade. Em maio, ondas } \\
\text { derrubaram as muretas de proteção da } \\
\text { praia e invadiram garagens de prédios }\end{array}$ \\
\hline $\begin{array}{l}\text { Os solos congelados próximos } \\
\text { ao Pólo Norte vão derreter. } \\
\text { O gelo flutuante do Ártico vai } \\
\text { derreter, mudando correntes } \\
\text { marinhas. Parte do Atlântico } \\
\text { Norte ficará mais fria }\end{array}$ & $\begin{array}{l}\text { A espessura da camada de gelo } \\
\text { do Ártico está } 40 \% \text { menor durante } \\
\text { a primavera e o verão do que há } \\
30 \text { anos - derrete cerca de } 8 \% \text { por } \\
\text { década. Nesse ritmo, no verão de } \\
2060 \text { não haverá mais nenhum gelo }\end{array}$ & $\begin{array}{l}\text { O aumento de } 2 \text { graus na temperatura } \\
\text { em áreas de solo congelado no norte da } \\
\text { Rússia, como na região de Yakutsk, levou } \\
\text { a uma diminuição de } 50 \% \text { da resistência } \\
\text { do solo. Cidades inteiras estão ruindo }\end{array}$ \\
\hline $\begin{array}{l}\text { O aquecimento da temperatura } \\
\text { na superfície dos oceanos } \\
\text { aumentará a incidência e a } \\
\text { força dos furacões. Áreas que } \\
\text { não tinham furacões poderão } \\
\text { passar a sofrer com o fenômeno }\end{array}$ & $\begin{array}{l}\text { Pesquisas recentes indicam que } \\
\text { a freqüencia e a intensidade dos } \\
\text { furacões de categoria } 4 \text { e } 5 \text {, os mais } \\
\text { fortes, quase dobraram em } 30 \text { anos. } \\
\text { Nos últimos } 20 \text { anos, o número de de- } \\
\text { sastres naturais mais que dobrou. São } \\
\text { cerca de } 800 \text { por ano }\end{array}$ & $\begin{array}{l}\text { Indaiatuba, no interior paulista, foi } \\
\text { atingida neste ano por um tornado que } \\
\text { causou prejuízos de R\$ } 97,2 \text { milhões. No } \\
\text { ano passado, um furacão atingiu parte da } \\
\text { costa de Santa Catarina e do Rio Grande } \\
\text { do Sul e causou prejuízo de mais de R\$ } \\
1 \text { bilhão. Foi o primeiro fenômeno desse } \\
\text { tipo a acontecer no Atlântico Sul }\end{array}$ \\
\hline $\begin{array}{l}\text { A Floresta Amazônica ficará } \\
\text { mais quente e, talvez, mais } \\
\text { seca e, portanto, vulnerável a } \\
\text { queimadas. Partes dela poderão } \\
\text { virar quase um cerrado }\end{array}$ & $\begin{array}{l}\text { A temperatura média da região } \\
\text { amazônica aumentou 0,56 grau nos } \\
\text { últimos } 20 \text { anos }\end{array}$ & $\begin{array}{l}\text { Quatro municípios decretaram estado de } \\
\text { emergência na semana passada devido } \\
\text { ao baixo nível dos rios Solimões e Negro, } \\
\text { que está em } 16 \text { metros, índice quase } \\
\text { tão baixo quanto o recorde histórico, de } \\
1963\end{array}$ \\
\hline
\end{tabular}

Fonte: Revista Época, Edição/n³86, 10 de outubro de 2005. Source: Epoca Magazine, Edition $/ n^{\circ} 386,10^{\text {th }}$ of October of 2005.

Ao optar por estas estratégias, a mídia ajuda a maximizar a percepção dos riscos frente aos impactos das mudanças climáticas, situando o problema no tempo presente, sem deixar de prever os impactos futuros (re)significando, assim, o Aquecimento Global com mecanismos inteligíveis e facilmente perceptíveis ao imaginário da população.

Com isso, a mídia contribui para divulgação de diversos discursos sobre o meio ambiente, inserindo-os no processo de mercantilização da natureza em detrimento do discurso que privilegia a luta por justiça ambiental.

\section{Bibliografia}

Acselrad, Henri. (2010). Ambientalização das lutas sociais: o caso do movimento por justiça ambiental. Estudos Avançados, vol 24, n. 68, p. 103-119.

Beck, U. (1992). Risk society. Towards a new modernity. Londres: Sage Publications.

COMISSÃO MUNDIAL SOBRE MEIO AMBIENTE E DESENVOLVIMENTO (CMMAD). (1988) Nosso Futuro Comum. Rio de Janeiro: Editora da Fundação Getulio Vargas. 
Costa, S. S. (2011). Seguroambiental: garantia de recursos para a reparação de danos causados ao meio ambiente. Brasília (Tese de Doutorado), p. 246.

Guivant, Julia S. (2001). A teoria da sociedade de risco de Ulrich Beck: entre o diagnóstico e a profecia. Estudos Sociedade e Agricultura, 16. p. 95-112.

Hannigan, J. (1995). Sociologia Ambiental: a formação de uma sociologia ambiental. Lisboa: Instituo Piaget.

Lipovetsky, G. (2007). A felicidade paradoxal: ensaio sobre a sociedade de hiperconsumo. São Paulo: Companhia das Letras.

Montibeller, G., Souza, G. C., Bôlla, K. D. S. (2012). Economia ecológica e sustentabilidade sócio ambiental. Revista Brasileira de Ciências Ambientais, n. 23, p. 25-35

Oliveira, L. D. (2012). Da Eco 92 à Rio+20: uma breve avaliação de duas décadas. Boletim Campineiro de Geografia, vol 2, n. 3, p. 479-499.

Sachs, W. (2000). Dicionário do desenvolvimento: guia para o conhecimento como poder. Petrópolis: Vozes.
Schmidt, Luísa (2008). Comunicar a ciência: o papel dos media e os problemas científico-ambientais, $\mathrm{p}$. 85-112.

Souza, L. B., Zanella, M. E. (2009). Percepção de Riscos Ambientais: teoria e aplicações. Fortaleza, Edições UFC, p. 240.

Veyret, Y. (2007). Os Riscos: o homem como agressor e vítima do meio ambiente. São Paulo: Contexto.

Whyte, A. V. T. (1985). Perception. [Pp 403-436] In: R. W. Kates, J. H. Ausubel, e M. Berberian. Climate Impact Assessment: Studies of the interaction of climate and society. ICSU/SCOPE Report, n. 27. Chichester: John Wiley.

Zangalli Jr, P. C. (2014). Entre a ciência, a mídia e a sala de aula: contribuições da geografia para o discurso das mudanças climáticas globais. São Paulo, Cultura Acadêmica.

Zangalli Jr, P. C. (2013). Sustentabilidade Urbana e as certificações ambientais na construção civil. Revista Sociedade e Natureza, vol. 25, n.2. p. 291-302. 